\title{
Co-Cr-Mo-W powder obtained by mechanical alloying
}

\author{
Alexandre Fernandes Habibe ${ }^{1,2}$, Jefferson Fabrício Cardoso Lins ${ }^{1}$, \\ Bruno Galvão Simba ${ }^{3}$, Roberto de Oliveira Magnago ${ }^{2,3}$, \\ Luiz Fabiano de Sá ${ }^{2}$, Claudinei dos Santos ${ }^{1,3}$
}

\author{
${ }^{1}$ Universidade Federal Fluminense - Escola de Engenharia Industrial Metalúrgica de Volta Redonda, UFF/EEIMVR Av. \\ Trabalhadores,420, Vila Santa Cecília, CEP: 27255-125, Volta Redonda-RJ, Brazil. \\ ${ }^{2}$ Centro Universitário de Volta Redonda - Pró-Reitoria de Pesquisa e Extensão, UNIFOA, Av. Paulo Erlei Alves Abran- \\ tes, 1325, Três Poços, 27240-560, Volta Redonda-RJ, Brazil. \\ ${ }^{3}$ Universidade do Estado do Rio de Janeiro - Faculdade de Tecnologia - UERJ/FAT, Rod. Presidente Dutra, km 298, Polo \\ Industrial, CEP: 27537-000, Resende, RJ, Brazil. \\ e-mail: alexandre.habibe@foa.org.br, jfclins@metal.eeimvr.uff.br, claudineisvr@gmail.com, luizfabianode- \\ sa@gmail.com, roberto.magnago@gmail.com, brgalvao@yahoo.com.br
}

\begin{abstract}
New techniques for manufacturing of biomaterials using additive/substrate manufacturing such as melting laser sintering (SLM) or CAD/CAM milling use micrometric metal powders to build custom parts. CoCrMo alloys are commonly used as biomaterials due to biocompatibility, high corrosion resistance and good mechanical properties. In this work, $\mathrm{Cr}$-Co-based powder was obtained by mechanical alloying of $\mathrm{Cr}$-Co-Mo-W alloy, using different Ball/Powder-Ratios (BPR) and thermal treatments. The powders were deagglomerated and characterized by X-ray diffraction (XRD) and Scanning electron microscopy (SEM). Based on SEM micrographs, the particle size analysis was used to compare the particles spheroidizing degree, using Feret's diameter. The XRD patterns shown $\mathrm{Co}_{\text {(solid-solution) }}$ as crystalline phase. The results of particles size indicates a decrease of Feret's diameter in BPR (Ball/Powder-Ratio) from 4:1 to 6:1 understanding that from this ratio there is no significant decrease of this relation but there is an average size increase with losses in morphological aspect. The comparison between atomized powders and powder developed in this work indicates that atomized products present relation close to one which indicates there is uniformity in the particles spherical shape. Comparing ground powders from 6:1 ratio (before and after thermal treatment) there is a considerable decrease of Feret's diameter being it decreased from 1.75 to 1.4 , an increase of about $46 \%$ in particles spheroidizing.
\end{abstract}

Keywords: Co-Cr-Mo-W alloy, High-Energy Ball Milling, powder morphology; characterization .

\section{INTRODUCTION}

A revolution in the field of prostheses and implants development is occurring with the use of manufacturing processes for fast-prototyping systems using digital image [1-3]. Among fast prototyping systems the most popular is CAD/CAM, Computer-Aided Design/Computer-Aided Manufacturing, in which a model is scanned through 3D scanning, and the software simulates the forms, and reports to a grinding system, which then performs the machining of components [2, 3].

CoCrMo alloys are commonly used for orthopedical implants or dental restorations due to its high corrosion resistance, good mechanical properties and biocompatibility. Dental components have been produced from these alloys by prototyping techniques, classified in two groups: additive manufacturing, such as Selective Laser Melting (SLM) technique and subtractive manufacturing, such as the milling of premanufactured materials assisted by CAD/CAM (Computer Aided Design/Computer-Aided Manufacturing) [4-7].

Selective laser Melting (SLM) [8-11] is a sintering technique, where the components developed in the 3D software are manufactured by depositing thin layers of powders with simultaneous in situ sintering, allowing the fabrication of any format with an accurate micrometer-scale. The construction time is similar with the manufacturing route for CAD/CAM but its main advantages are: dimensional accuracy, the possibility of several geometries, no use of machining tools and especially the elimination of losses in raw materials, as the raw material is fully converted into the final product [2]. In both processes, it is necessary the use of raw materials as powder. Thus, viable technical and economic manufacturing processes are necessary in order to 
obtain powders which allow the achievement of sintered or pre-sintered workpieces.

The High-Energy Ball Milling [11-12], also called mechanical alloying, is a complex process that involves the optimization of a relevant number of milling-parameters to obtain phases and/or a designed microstructure in final product. Some of the very relevant parameters, considering the final configuration of powder are: material shape, grinding configuration, grinding speed and time, kind, size and particle size distribution in grinding means, mass ratio regarding powder and balls, space available considering spheres and powder, grinding atmosphere and temperature.

The obtaining of Co-Cr-Mo system powders through mechanical alloying process has been studied by several authors [13-15] and all affirm that the mentioned metallic system possesses fragile characteristics that are likely to comminute in nanometric fragmentation scales, however the heterogeneous morphological characteristic of this powder limits its use in accuracy process as powder metallurgy for CAD/CAM milling or Solid State Sintering. The aim of this work was to study the effect of grinding ball load behavior on grinding of Co-Cr-Mo-W alloy system, and subsequently, heat treatments aiming the obtaining of spherical particles.

\section{MATERIALS AND METHODS}

\subsection{Alloy obtaining}

The raw material used in this work was a Co-Cr-Mo-W metallic alloy, whose chemical composition is shown in Table 1. For comparative analysis, the Co-Cr-Mo-W commercial powder (EOS-SP2 ${ }^{\mathrm{TM}}$ Germany) was used. The metallic alloy was obtained through conventional vacuum casting. The metallic ingots ( $100 \mathrm{~mm}$ diameter and $500 \mathrm{~mm}$ length) were cleaned for eliminating superficial foulness. This material was machined by turning, using lathe ROMITM-ID20, resulting in chips which were chemically etched, removing cutting fluids or any other impurity generated in machining process.

Table 1: Composition of Co-Cr-Mo-W alloys used in this work.

\begin{tabular}{l|c|c|c|c|c|c|c|c|c}
\hline \multicolumn{1}{c}{ CONTENTS (wt. \%) } \\
\hline MATERIAL & Co & Cr & Mo & W & Si & Mn & Fe & Others & Balance \\
\hline DEVELOPED ALLOY & 65.1 & 22.1 & 5.6 & 5.8 & 0.6 & 0.1 & 0.3 & 0.3 & 100 \\
\hline EOS $^{\text {TM }}$ SP2 & 61.6 & 25.6 & 6.2 & 5.5 & 0.5 & 0.1 & 0.2 & 0.3 & 100 \\
\hline
\end{tabular}

\subsection{High-energy milling process}

The Co-Cr-Mo-W chips were grounded in high-energy ball mill model Spex ${ }^{\mathrm{TM}} 8000 \mathrm{D}$, with two milling bowls using the following process parameters: 2 tungsten-carbide/cobalt bowls, WC-Co, with $225 \mathrm{ml}$ and WC-Co balls, with $10 \mathrm{~mm}$ diameter; Spinning speed of $200 \mathrm{rpm}$; Grinding time of $60 \mathrm{~min}$; ball to powder mass ratios of $4: 1,6: 1,8: 1$ and 10:1.

WC-Co grinding bowls and balls were used due to their high hardness and wear resistance. These properties reduce the possibility of powder contamination, which could alter the desired properties for the final products. The use of different ball to powder mass ratios (BPR) had as an aim the study of this ratio in grinding process efficiency.

The chips from different mass ratios were put in grinding bowl and properly handled in a glove box in argon environment. For this work it was used the procedure of short stops of 2 min to each 15 min of grinding, and subsequently reversal rotation. This procedure aims a better sample homogenization, making difficult the possibility of "routes" for the balls, which would concentrate the hits in some specific regions of the material.

\subsection{Thermal Treatment}

Thermal treatment process used powders with BPR of 6:1 ground for 60min being treated in tubular oven Maitec ${ }^{\mathrm{TM}}-\mathrm{F} 1150 \mathrm{C}$. In this procedure the samples were vacuum encapsulated in silica tubes and thermally treated to final temperatures of $900{ }^{\circ} \mathrm{C}$ or $1000{ }^{\circ} \mathrm{C}$ with isothermal holding time of $120 \mathrm{~min}$, using controlled heating and cooling rates of $10{ }^{\circ} \mathrm{C} / \mathrm{min}$ and $15^{\circ} \mathrm{C} / \mathrm{min}$ respectively, so from spherical diffusion they could reach suitable spheroidizing levels. After thermal treatments the particles were deagglomerated in agate mortar and afterwards separated by particle size by sieve shaking.

\subsection{Characterizations}


The crystalline phases present in the powders studied, were identified by X-ray diffraction (XRD), (Shimad$\mathrm{zu}^{\mathrm{TM} X R D 6100)}$ using $\mathrm{Cu}-\mathrm{K} \alpha$ radiation with scanning range between $10^{\circ}$ and $80^{\circ}$, step of $0.02^{\circ}$ and speed of $5 \mathrm{~s} /$ counting point. The peaks were identified by comparison with JCPDS files [16]. Scanning electron microscopy (SEM) analyses of powders were performed by Hitachi ${ }^{\mathrm{TM} T M} 3000$ microscope. Particles were deposited, as received, on carbon tape and analyzed by SEM under different magnifications to evaluate morphological aspects.

\subsection{Morphology and particles quantification}

The analyses of particle size quantification were realized according to ASTM E1382 [17, 18]. The counting of particle size of ground powders was realized using software Image $J$ with a minimum population of 1000 particles. Based on SEM images the particle size analysis was used to compare the particles spheroidizing degree. For this process it was used Feret's diameter considering variables "Feret $X$ " and "Feret $Y$ " which are coordinates for the first point in the line that represents maximum Feret (or as called in Image J, Feret). A consistent parameter to point a particle spheroidizing can be implied by Feret's diameter which is obtained by the relation between Feret and minimum Feret found in image analysis.

\section{RESULTS AND DISCUSSION}

\subsection{Characterization of raw materials}

Fig.1 presents XRD pattern of chips from the machined alloy obtained from casting. The XRD patterns presented indicate metallic cobalt as the only crystalline phase. The low intensity of crystalline peaks diffraction indicates a disorder level in its original structure which tends to be organized in further thermal treatments. The presence of only metallic cobalt phase indicates that the components form a solid solution with this metal. Based on chemical analyses presented in Table 1, cobalt, Co, is found in bigger content, superior to $60 \%$ in weight. Considering phase diagrams of this composition and the characteristics of each metal present in these alloys, it is expected that the metals atomic organization prioritizes the formation of a cobalt solid solution $\left(\mathrm{Co}_{\mathrm{sS}}\right)$. In fact, the solubility analysis applying the solubility rules for all metals they present atomic similarity with atomic radius of $0.125 \mathrm{~nm}, 0.140 \mathrm{~nm}, 0.136 \mathrm{~nm}$ and $0.137 \mathrm{~nm}$ for Co, Cr, Mo and $\mathrm{W}$, respectively. Moreover, all the solutes present body-centered cubic (BCC) crystal structure so this similarity also contributes for Co high solubility with these solutes.

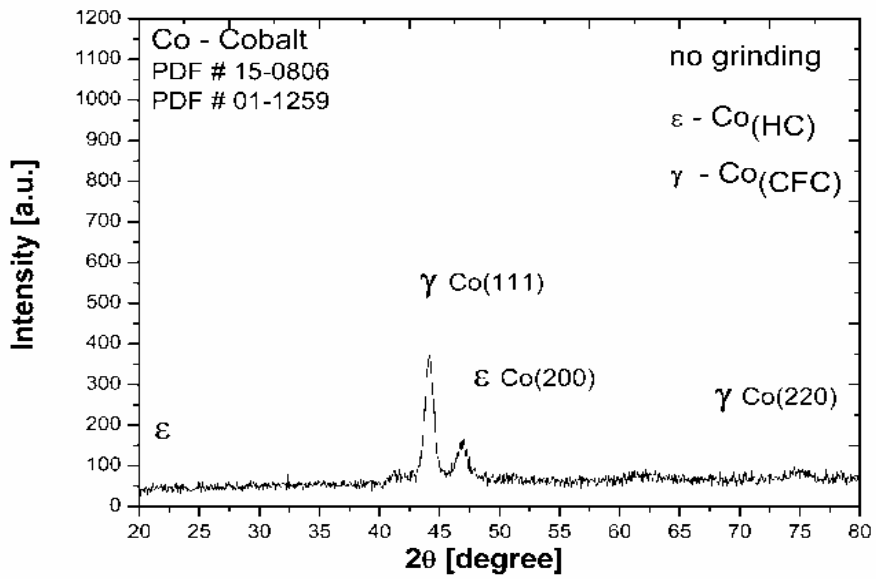

Figure 1: XRD patterns of chips from Co-Cr-Mo-W alloy.

The Co-Cr-Mo-W alloy interplanal distance of (111) plan of face-centered cubic (FCC) crystal structure is $2.06 \AA$ whereas the theoretical interplanal distance is $2.046 \AA$, which means that the Co-Cr-Mo-W alloy obtained an interplanal distance increase and this difference also refers to the incorporation of $\mathrm{Cr}$ and Mo atoms in Co crystalline lattice. Based on XRD patterns presented in Fig.1, it can be seen that the alloy presents mostly phase $\gamma$ Co of FCC crystal structure $[19,20]$.

Cobalt presents allotropic transformation where close-packed hexagonal $(\mathrm{CPH})$ crystal structure is stable at room temperature until $450{ }^{\circ} \mathrm{C}$. From this temperature the stable structure becomes FCC crystal structure. The transformation from $\mathrm{CPH}$ (called $\varepsilon$ ) to $\mathrm{FCC}$ (called $\gamma$ ) represented by $\mathrm{CPH} \rightarrow \mathrm{FCC}_{\left(449{ }^{\circ} \mathrm{C} \text { - heating) }\right.}$ 
is relatively simple during the metal heating process whereas the transformation $\mathrm{FCC} \rightarrow \mathrm{CPH}_{(449}{ }^{\circ} \mathrm{C}$ - cooling) which occurs during cooling is usually incomplete due to the structures transformation energy to be very close.

The allotropic transformation nucleation in Co system is based on the concept which says a failure in the matrix $\alpha$ piling can be considered an embryo of $\varepsilon$ phase (and vice-versa). The stacking fault is literally a failure on the sequence of close-packed plans stacking of crystalline structure. For example, in the FCC crystal structure the stacking sequence is $\mathrm{ABC} / \mathrm{ABC} / \mathrm{ABC}$. In $\mathrm{CPH}$ crystal structure there is a stacking sequence $\mathrm{AB} / \mathrm{AB} / \mathrm{AB} / \mathrm{AB}$. The probability of an stacking fault in a crystal is inversely related to the stacking fault energy (SFE) for a particular metal so pure cobalt presents an SFE of about $2 \times 10^{-2} \mathrm{~J} / \mathrm{m}^{2}$, which is very low when compared to other metals. For example the SFE for aluminum is about $250 \times 10^{-6} \mathrm{~J} / \mathrm{m}^{2}$ so this means the probability of stacking fault in pure cobalt is high [21].

The cobalt allotropic transformation is slow, forming a metastable FCC crystal structure with low SFE acting as an obstacle difficult the movement of discordances. This way, a higher shock resistance, thermal fatigue and creep are obtained. Besides the low SFE the FCC crystal structure, especially of cobalt alloys, presents a high recrystallization temperature improving wear resistance at high temperatures. According to VARANA et al [22] the slow allotropic transformation can be explained by low Gibbs free energy $(\Delta \mathrm{G})$ from $\gamma$ to $\varepsilon$ (approximately $12 \mathrm{~J} / \mathrm{mol}$ ). In steel for example the martensitic transformation $\Delta \mathrm{G}$ from a FCC crystal structure to tetragonal body-centered tetragonal (BCT) crystal structure is approximately $-1213 \mathrm{~J} / \mathrm{mol}$ which means the steel $\Delta \mathrm{G}$ is approximately 100 times higher than the cobalt one.

The addition of alloy elements in cobalt matrix can change the allotropic transformation temperature for it can cause stabilization in CPH crystal structure present at low temperatures or in FCC crystal structure present at high temperatures. CPH crystal structure is stabilized by chromium, molybdenum and tungsten and FCC crystal structure is stabilized by iron and nickel. This could explain the $\gamma \mathrm{Co}$ (FCC crystal structure).

Fig.2 presents SEM images focusing morphological aspects of chips after turning. It is known [23, 24] that shearing bands are observed in machined Co-Cr-Mo chips. The visual aspect indicates that besides the shearing bands observed the material under impact deformations is less ductile than other metals as low carbon steel or aluminum. As a typical example of material/alloy similar to the one proposed in this work it is presented a some data of EOS ${ }^{\mathrm{TM}} \mathrm{SP} 2$ material specifications $[25,26]$ which indicate rupture strength of 800 $\mathrm{MPa}$, yield strength of $600 \mathrm{MPa}, 10 \%$ elongation at rupture (minimum) and typical range of $14 \pm 2 \%$, Young modulus of $170 \mathrm{GPa}$ and hardness of $320 \mathrm{HV}$ (typical $360 \pm 20 \mathrm{HV}$ ). Comparing to steel and aluminum which present elongation of around 20 to 30 and $35 \%$ respectively, this material presents bigger limitations to plastic deformation which tends to be easier for grinding process.
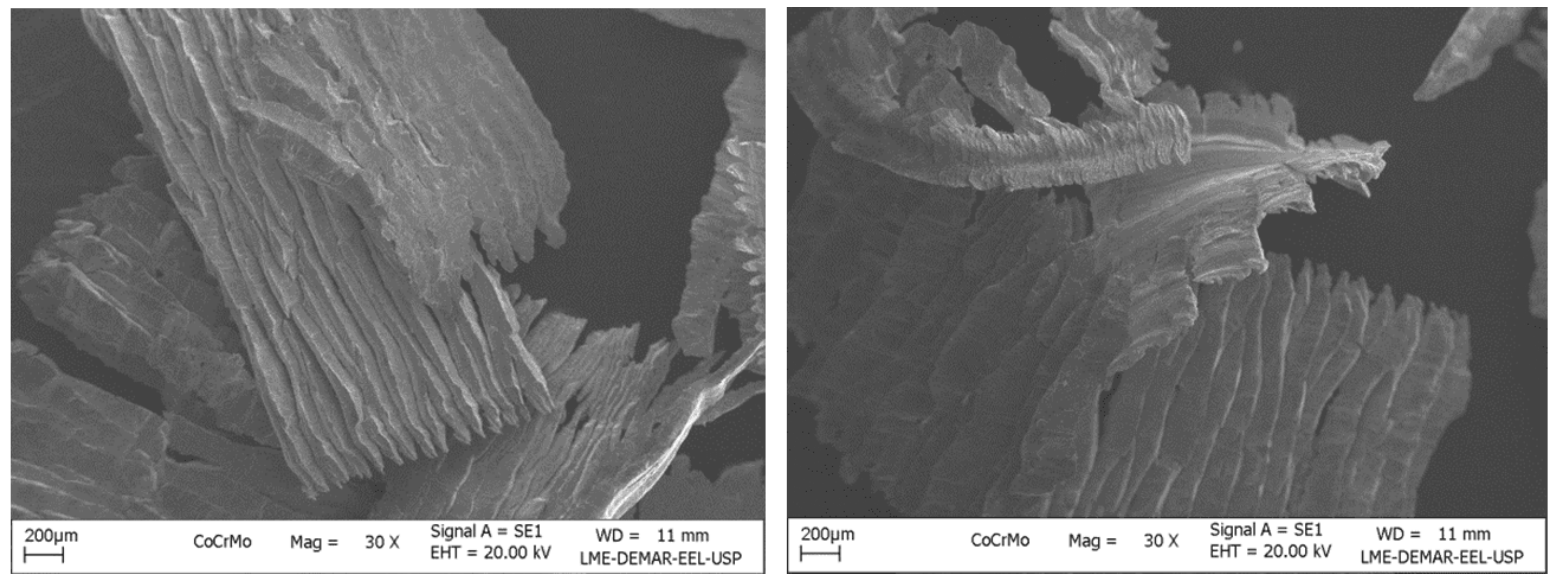

Figure 2: Co-Cr-Mo-W chips morphology machined by turning.

Fig. 3 presents the XRD pattern of commercial powder. It is also observed that only $\gamma \mathrm{Co}_{\mathrm{FCC}}$ phase was detected, indicating that the components form a solid solution with metallic cobalt. 


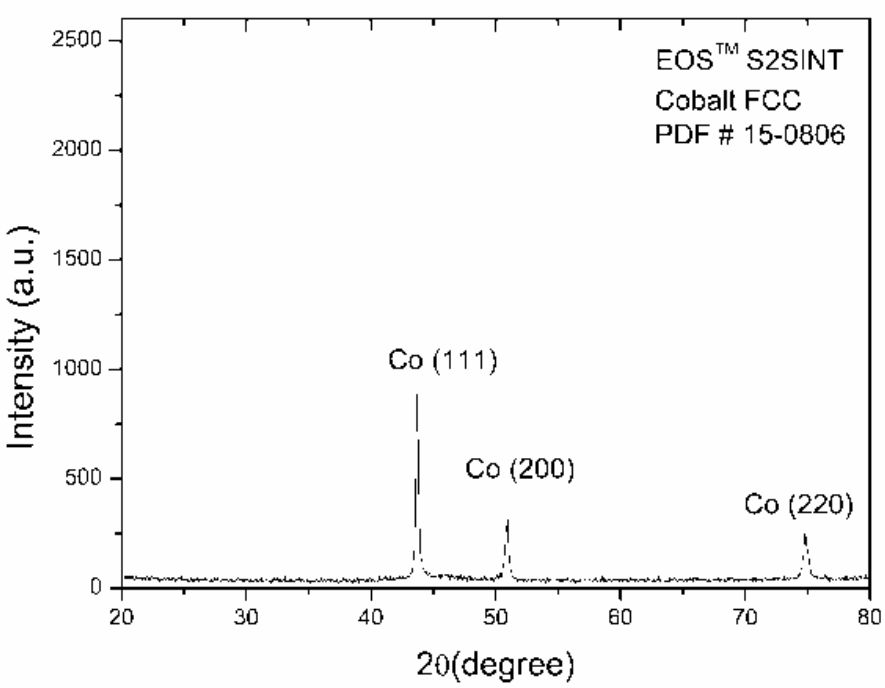

Figure 3: XRD pattern of commercial powder from Co-Cr-Mo-W alloy.

\subsection{Characterization of milling}

Fig.4 presents representative SEM images of ground powders in different BPR with grinding time fixed of 60 min. Fig. 4(a) which indicates ball to powder mass ratio of 4:1, shows there is a very big variation in particle size and morphology. It can be seen that there is a presence of particles 6 to 8 times bigger than the population of smaller particles. Moreover, powders of heterogeneous morphology are found with low powder spheroidizing. In grinding realized with BPR of 6:1, Fig. 4(b), the powders present better size and shape uniformity. This condition of grinding reaches efficient levels of particles homogeneity when compared to BPR of 4:1 however with low spheroidizing.

The raising of BPR of 8:1 and 10:1 leads to a sharp raise of particles sizes, Fig.4(c) and 4(d). This behavior, usual in ductile materials, is called cold welding and it happens according to high levels of impact to which the metal is under during grinding in planetary mill. Co-Cr-Mo-W alloy presents low ductility which facilitates the material to suffer decrease of particle size in primary levels of deformation. Observation of the results indicates that an acceptable limit of WC-Co balls to be used in this grinding system would be in the ratio of $6: 1$

Fig. 5 presents XRD pattern of ground powders in different BPR. Compared to XRD patterns of chips, it is observed a decrease of peak intensity of $\varepsilon$ Co according to the increase of BPR of $4: 1$ and $6: 1$. Powder XRD patterns of 8:1 and 10:1 ratios present peaks with higher intensity related to ground powder of 6:1 ratio, which can be related to the increase of particles average size and to re-welding process referred to the material $[12,27]$.

\subsection{Characterization after thermal treatments}

Based on grinding process results, it was used Co-Cr-Mo-W ground powder with ratio of 6:1 which presents morphological characteristics promising for posterior thermal treatments to those the powder will be submitted. Results of morphological characterization performed in thermally treated $\mathrm{Co}-\mathrm{Cr}-\mathrm{Mo}-\mathrm{W}$ ground powders (BPR 6:1), and different BPR (4:1, 8:1 and 10:1) are presented in Fig. 6. The results indicate a tendency to particle spheroidizing. Comparison results among different grinding conditions are presented in Fig. 7. 

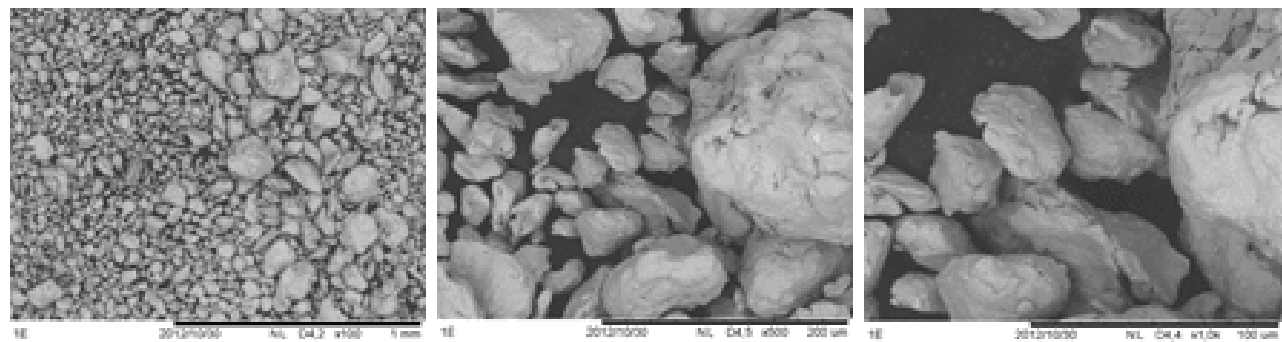

a) $4: 1$
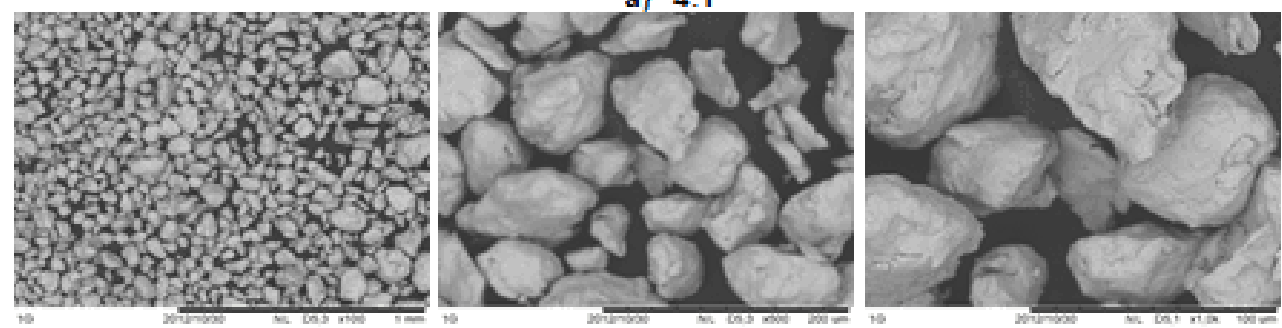

b) $6: 1$
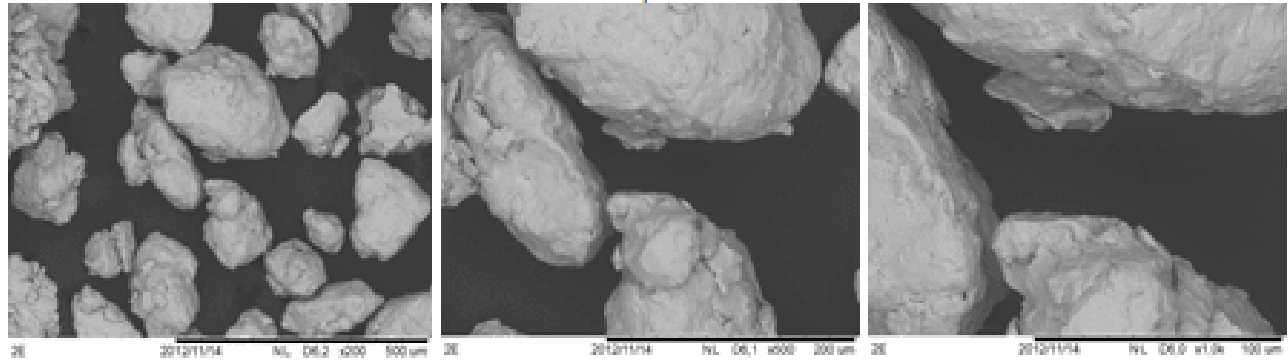

c) $8: 1$
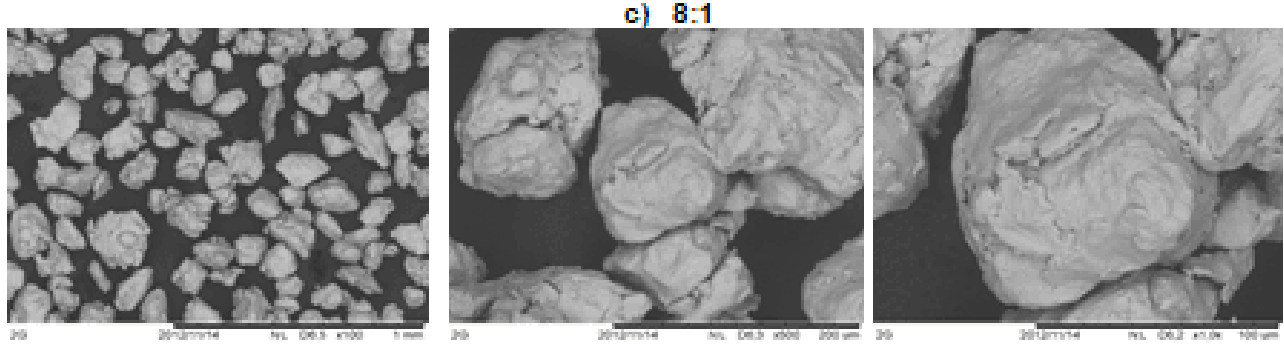

d) $10: 1$

Figure 4: SEM images of ground particles with BPR of a) 4:1, b) 6:1, c) 8:1 and d) 10:1, for 60min (magnification: 100x (left), 500x center and 1000x (right). 


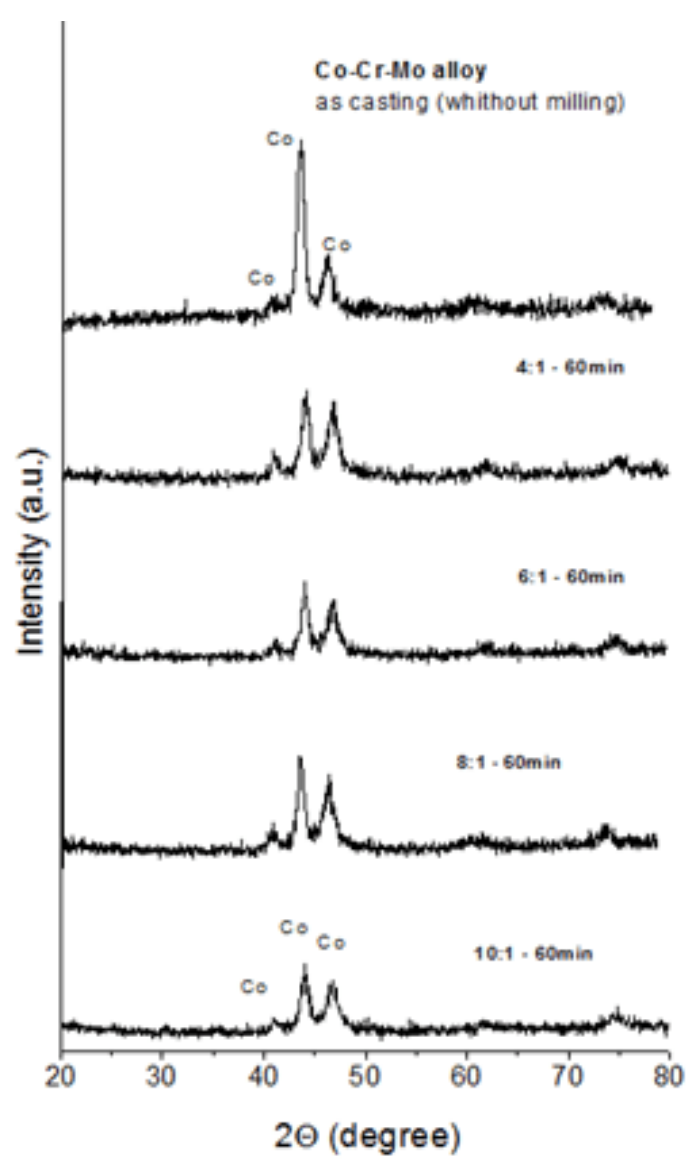

Figure 5: XRD patterns of powders ground for 60min in different BPR .
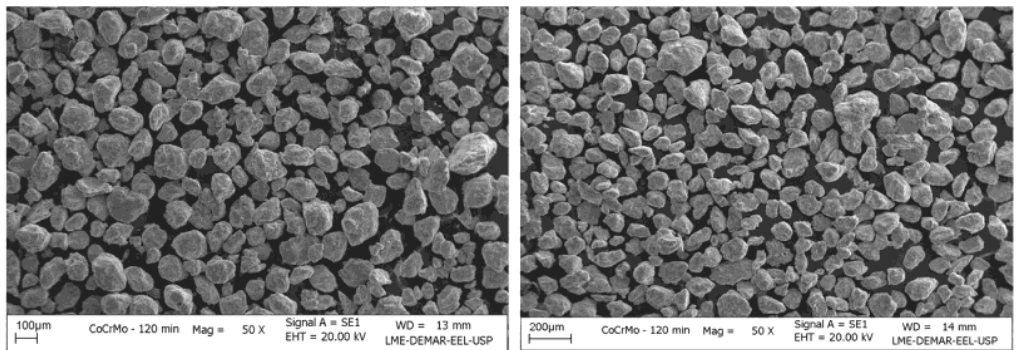

(a)

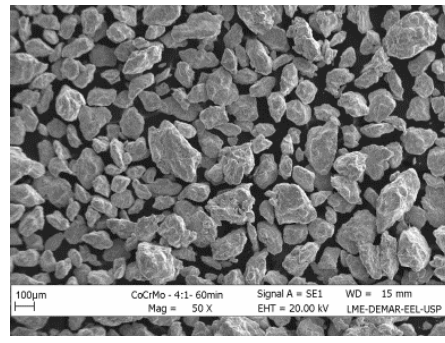

(b)

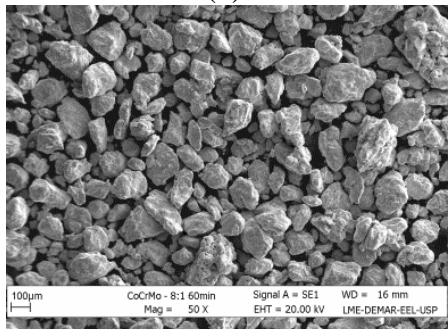

(c)

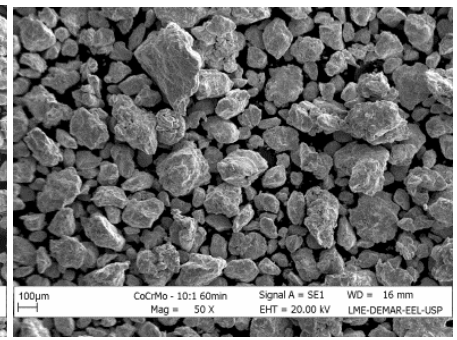

(d)

Figure 6: SEM images of Co-Cr-Mo-W powders with: a) BPR of 6:1 submitted to thermal treatment a) at $900{ }^{\circ} \mathrm{C}$ and b) at $1000{ }^{\circ} \mathrm{C}$ - $120 \mathrm{~min}$; b) 4:1- $\left.\left.60 \mathrm{~min}, \mathrm{c}\right) 8: 1-60 \mathrm{~min} ., \mathrm{d}\right) 10: 1$ - $60 \mathrm{~min}$; 


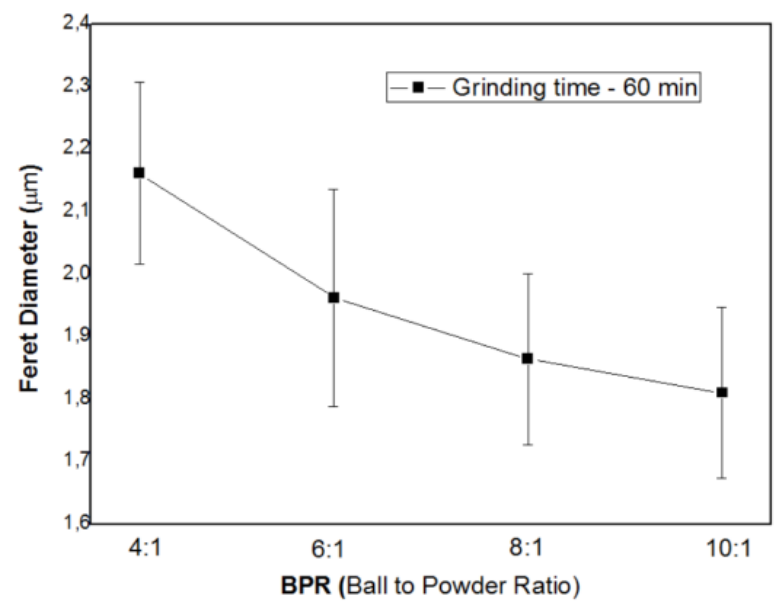

Figure 7: Feret's diameter according to grinding parameters.

According to SEM images presented in Fig. 4 the results indicate a decrease of Feret's diameter in BPR from 4:1 to $6: 1$ understanding that from this ratio there is no significant decrease of this relation, but there is an average size increase with losses in morphological aspect.

Fig. 8 shows a comparative among 6:1 ratio powders before and after heat treatment and atomized commercial powders $\left(\right.$ EOS $^{\mathrm{TM}}$ ) used in SLS. The comparison between atomized powders EOS ${ }^{\mathrm{TM}}$ and powder developed in this work indicates that atomized products present relation close to one which indicates there is uniformity in the particles spherical shape according to SEM images presented in Fig. 6.

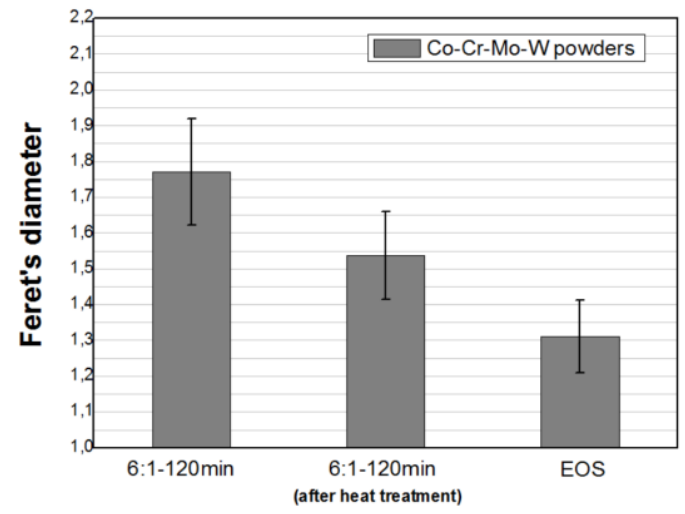

(a)

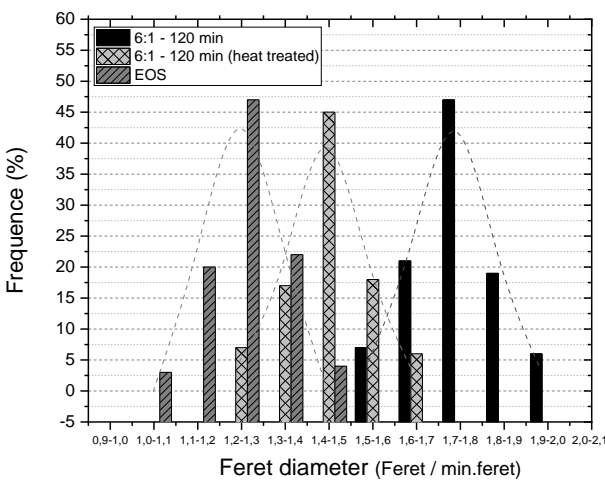

(b)

Figure 8: (a) Feret's diameter and (b) particles size distribution for commercial particles and ground powders for 120 min before and after thermal treatment.

Comparing ground powders from 6:1 ratio before and after thermal treatment, there is a considerable decrease of Feret's diameter being it decreased from 1.75 to 1.4, an increase of about $46 \%$ in particles spheroidizing. The use of thermal treatment parameters proposed in this work $\left(100{ }^{\circ} \mathrm{C}-120 \mathrm{~min}\right)$ allows $\mathrm{Co}-\mathrm{Cr}$ Mo-W powders to experiment a considerable superficial diffusivity, which allows the particles spheroidizing to satisfactory levels according to MICULESCU et al. [21]. Co-Cr (according ASTM F75) diffusivity at 800 ${ }^{\circ} \mathrm{C}$ is approximately $0.052 \mathrm{~cm}^{2} / \mathrm{s}$ and considering laser sintering process data which leads to complete densification of this composition at $1320{ }^{\circ} \mathrm{C}$ the temperature of the thermal treatment was responsible for the increase of particles spheroidizing.

\section{CONCLUSIONS}

The results indicate decrease of powders size ground in high energy of about $50 \%$ when submitted to grinding for 120 min using ball to powder mass ratio of 6:1. High Energy Ball Milling was efficient for Co-CrMo-W alloy. It is important to highlight that there is also a tendency to spheroidizing according to grinding time. Grinding process allows semi-spheroidizing agglomeration of particles with average size decrease understanding that the ideal size condition must be investigated according to the laser beam intensity to be used in sintering and the use of thermal treatment presented at first a tendency to spheroidizing when heated at $1000{ }^{\circ} \mathrm{C}$ and thermal holding time of $120 \mathrm{~min}$. 


\section{ACKNOWLEDGMENTS}

The authors thank the FINEP (01-10.0805.00) and FAPERJ (E-26. 111.789/2013) for financial support.

\section{BIBLIOGRAPHY}

[1] VAN HOOREWDER, B., LIETAERT, K., NEIRINCK, B., et al.,. CoCr F75 scaffolds produced by additive manufacturing: Influence of chemical etching on powder removal and mechanical performance. $J$ Mech Behav Biomed Mater v. 70, p. 60, 2017.

[2] ANUSAVICE, K.J., SHEN, C., RAWLS, H.R., Phillips - science of dental materials, Elsevier Health Science, $12^{\text {th }}$ edition, USA, p. 538, 2014.

[3] BILGIN, M.S., ERDEM, A., DILBER, E., et. al.,"Comparison of fracture resistance between cast, CAD/CAM milling, and direct metal laser sintering metal post systems", Journal of Prosthodontic Research, 2016, v. 60. n.1, pp: 23-28, 2016.

[4] CHEN, J., ZHANG, Z., CHEN, X., et al., Design and manufacture of customized dental implants by using reverse engineering and selective laser melting technology. J Prosthet Dent. v. 112, n. 5, pp.1088 1095, 2014.

[5] BARUCCA, G., SANTECCHIA, E., MAJNI, G., et al.,Structural characterization of biomedical Co-CrMo components produced by direct metal laser sintering. Mater Sci Eng C. v.48, pp. 263-269, 2015.

[6] STAWARCZYK, B., EICHBERGER, M., HOFFMANN, R., et al., A Novel CAD/CAM Base metal compared to conventional CoCrMo Alloys: An in-vitro Study of the Long-term Metal-ceramic Bond Strength. Oral Heal Dent Manag.; v. 23, n.2, pp. 446-452, 2014.

[7] GIRARDIN, E., BARUCCA, G., MENGUCCI, P., et al., Biomedical Co-Cr-Mo Components Produced by Direct Metal Laser Sintering. Mater Today Proc. v. 3, n.3, pp. 889-97, 2016.

[8] AYILDIZ, S., "The place of direct metal laser sintering (DMLS) in dentistry and the importance of annealing". Materials Science and Engineering: C, v. 52, n. 1, p. 343, 2015.

[9] ZHOU, Y., WEI, W., YAN, J., et al., Microstructures and metal-ceramic bond properties of Co-Cr biomedical alloys fabricated by selective laser melting and casting. Mater Sci Eng A, v. 759, pp. 594-602, 2019.

[10] DESPA, V., CAYANGIU, A., IVAN, I.A., "Mechanical Characteristics of CoCrMo alloys manufactured by laser sintering technology", Materials and mechanics, v. 8, n. 11, 2013.

[11] MALLIK, M.K., RAO, C.S., KESAVA, et al. "Effect of Heat treatment on hardness of Co-Cr-Mo- Alloy Deposited with laser engineered Net shaping", Procedia Engineering, v. 97, pp. 1718-1723, 2014.

[12] SURYANARAMA, C., "Mechanical alloying and milling", Progress in Materials Science, v. 46, pp. 1184,2001

[13] HULLER, M., CHERNIK, G.G., FOKINA, E.L., et al., "Mechanical alloying in planetary mills of high accelerations", Rev.Adv.Mater.Sci. v. 18, pp. 366-374, 2008.

[14] SANTOS, C., HABIBE, A.F., RODRIGUES JUNIOR, D., et al. "Microstructural characterization Of 66\%Co-28\%Cr-6\%Mo Dental Alloy Powder Obtained By High-Energy Ball Milling". Materials Science Forum, v. 802, pp. 51-55, 2014.

[15] BOLARÍN-MIRÓ, A.M., SÁNCHEZ-de-JESÚS, F., TORRES-VILLASENOR, G., et al. "Amorphization of Co-base alloy by mechanical alloying", Journal of Non-Crystalline Solids, v. 357 pp. 1705-1709, 2011.

[16] JCPDS Powder Diffraction File, Inorganic materials. Pennsylvania: Swarthmore, International Centre for Diffraction Data, 2010.

[17] SOILE P., Morphological image analysis: principles and applications. New York: Springer, 1999.

[18] ASTM- E1382, Standard Test Methods for Determining Average Grain Size Using Semiautomatic and Automatic Image Analysis, West Conshohocken, United States, p. 22, 2004

[19] NARAYAN, R. Biomedical Materials; Publisher Springer; ISBN 978-0-387-84871-6, p. 550 , 2009.

[20] BETANCOURT-CANTERA, J.A., et al., Extended solid solubility of a Co-Cr system by mechanical alloying, Journal of Alloys and Compounds, v. 529, p.58-62, 2012

[21] MICULESCU, M., COSMELEATÁ, G., BRÂNZEI, M. et al., "Thermal diffusivity of materials using flash method applied on CoCr alloys", U.P.B. Sci. Bull.v. 70 n. 2, pp. 1-11, 2008. 
[22] VARANA, R., "Structure - property investigation of Co-Cr-Mo alloys used in metal-metal total hip replacements"; Department of Mining and Metallurgical Engineering; Montreal - Canada, 1998.

[23] SANTOS, C., HABIBE, A.F., RODRIGUES JUNIOR, D., et al., "Effect of Ball-Powder Ratio in the High-Energy Milling of 66\%Co-28\%Cr-6\%Mo Dental Alloy", Materials Science Forum, v. 802, pp. 56-60, 2014.

[24] REIMANN, L.; DOBRANSKI, L.A., Influence of the casting temperature on dental Co-base alloys properties", Archives of Materials Science and Engineering, v. 60, pp. 5-12, 2013.

[25] TAKAICHI, A., SUYALA, T.U., NAKAMOTO, T., et al., "Microstructures and mechanical properties of Co-29Cr-6Mo alloy fabricated by selective laser melting process for dental applications", Journal of the mechanical behavior of biomedical materials v. 2, pp. 67-76, 2013.

[26] AKOVA T., UCAR Y., TUKAY A., et al., "Comparison of bond strength of laser-sintered and cast base dental alloy to porcelains", Dental materials, v. 24, n. 10, pp.1400-1404, 2008.

[27] KIS-VARGA, M., BEKE D.L., "Phase transitions in $\mathrm{Cu}-\mathrm{Sb}$ systems induced by ball milling", Materials Science Forum, v. 225-227, pp. 465-470, 1996.

\section{ORCID}

Alexandre Fernandes Habibe Jefferson Fabrício Cardoso Lins Bruno Galvão Simba Roberto de Oliveira Magnago Luiz Fabiano de Sá Claudinei dos Santos http://orcid.org/0000-0001-6409-3996

http://orcid.org/0000-0001-5106-4969

http://orcid.org/0000-0002-6375-6484

http://orcid.org/0000-0003-0910-1572

http://orcid.org/0000-0001-6838-3413

http://orcid.org/0000-0002-9398-0639 